\title{
Pequenos gestos, louváveis
Três contributos para a História do Teatro em Portugal
}

\section{Maria João Brilhante}
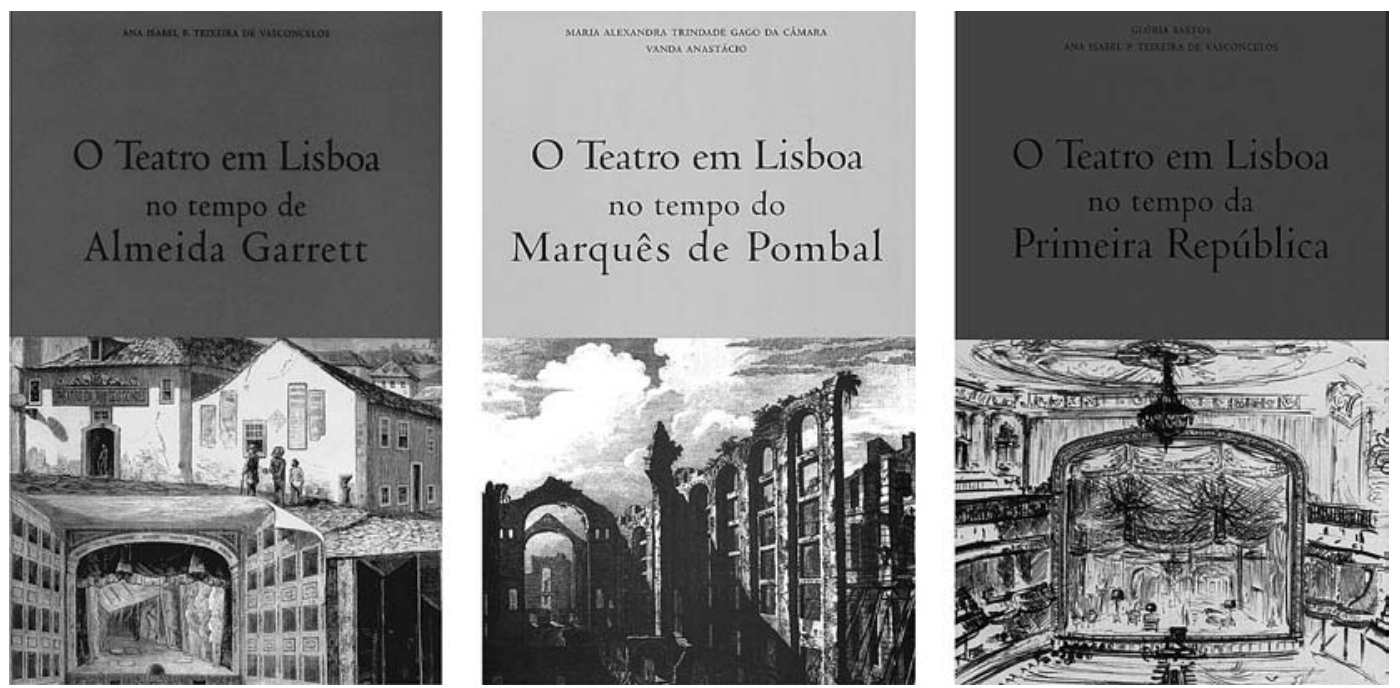

Ana lsabel P. Teixeira de Vasconcelos, $O$ teatro em Lisboa no tempo de Almeida Garrett, Lisboa, 1.P.M., Museu Nacional do Teatro, col. Páginas de Teatro, vol. 1, 2003, 151 pp.

Maria Alexandra Trindade Gago da Câmara / Vanda Anastácio, $O$ teatro em Lisboa no tempo do Marquês de Pombal, Lisboa, I.P.M., Museu Nacional do Teatro, col. Páginas de Teatro, vol. 11, 2004, 153 pp.

Glória Bastos / Ana lsabel P. Teixeira de Vasconcelos, O teatro em Lisboa no tempo da Primeira República, Lisboa, I.P.M., Museu Nacional do Teatro, col. Páginas de Teatro vol. 111, 2004, $171 \mathrm{pp}$.

Com algum atraso relativamente à data de edição, mas muito a tempo para poder ainda chamar a atenção dos leitores para a "novidade" que constitui a publicação de três estudos sobre teatro em Portugal, as linhas que se seguem pretendem, sobretudo, não deixar passar despercebido um projecto editorial e um trabalho de investigação que devem ser considerados exemplares.

0 referido carácter exemplar prende-se com o facto de estarmos perante um projecto que reúne o desejo de divulgar o espólio documental de um museu nacional e a vontade de fazer chegar a um público alargado o resultado da investigação de quatro estudiosas do teatro e da literatura dramática. Só por si, este propósito de ultrapassar o espaço normalmente fechado das instituições e academias merece a nossa atenção. Mas a possibilidade de o trabalho de investigação individual poder ser colocado ao serviço de um projecto colectivo deve ser também enaltecida, pois revela uma mudança de paradigma na investigação teatral e augura um futuro produtivo no que ao estudo do teatro diz respeito.

Posto isto, importa igualmente sublinhar que o desejo de divulgação e de alargamento do público leitor - como sabemos, ainda limitado em Portugal nesta área do saber - não transige com a qualidade dos objectos produzidos, já que estes resultam de trabalho rigoroso e respeitador dos princípios da investigação histórica. Por conseguinte, aliam o propósito de analisar e interpretar os dados disponíveis e pertinentes para o conhecimento da história do teatro em Portugal em períodos determinados à adequação desse conhecimento a um espectro alargado de leitores que engloba necessariamente aqueles que desconhecem de que é composto o complexo campo teatral.

Aliás, e como bem sublinha o prefaciador do volume III da colecção, o historiador do teatro Duarte Ivo Cruz, 
"O teatro em Lisboa no tempo da Primeira República traznos, com grande qualidade e rigor, essa visão, não complementar mas essencial do fenómeno teatral, na sua dimensão e produção artística e de inserção na sociedade, relativa a um dos momentos mais vivos e dinâmicos da cultura portuguesa" (p. 7). Trata-se, de facto, de concretizar - gesto por si só assinalável na nossa tradição historiográfica que se ocupa desta arte - uma concepção de teatro que se distingue da habitual assimilação entre teatro e literatura dramática. Se existe em cada um dos volumes um capítulo dedicado aos textos representados nos nossos palcos, a sua abordagem faz-se do ponto de vista do que podem significar a escolha das peças e a constituição de reportórios, logo, enquanto contribuição para o conhecimento das correlações entre teatro e sociedade, teatro e economia, teatro e poder, entre outras. Depois de constatarem o tratamento irrelevante dado nas histórias do teatro português a autores de textos que foram sucessos nos palcos da Primeira República, as autoras afirmam: "Neste âmbito, consideramos que é urgente um olhar não apenas do lado da produção escrita mas, sobretudo, virado para a recepção teatral, isto é, para os textos que efectivamente foram representados e para as suas repercussões no contexto cultural de então, porque são esses que, em primeiro lugar, tiveram eco no público e na imprensa. São essas as peças que, de alguma maneira, 'moldaram' o espectador da República e se 'ajustaram' ao seu gosto, constituindo o reportório de uma época" (p. 96).

Se um dos pontos de partida para a organização interna dos volumes consiste em procurar responder a questões aparentemente tão simples como: "A que assistiam os espectadores quando compravam um bilhete no Teatro da Rua dos Condes ou mesmo no Teatro Nacional D. Maria II?", ou "Como se desenrolava então uma noite de teatro?", "Quem escolhia as peças representadas?", "Eram sujeitas a algum tipo de censura?", "A quem pertenciam as companhias de teatro?", ou ainda "Seriam os actores profissionais daquele oficio?" (volume I, p. 11), a informação facultada ao leitor não fica pela anedota ou pela resposta pitoresca com que por vezes nos presentearam os memorialistas do passado. 0 discurso desses memorialistas, dos biógrafos de actores, dos cronistas e periodistas surge aqui cruzado com as fontes (legislação, contratos, contas e relatórios de companhias, etc.) que existem nos nossos Arquivos e que oferecem ainda um vasto campo a explorar. Por isso, a leitura quer da bibliografia consultada, quer das notas que vão identificando as fontes citadas ou utilizadas constitui a prova de que não nos é oferecida uma história "romanceada", interessada em colmatar lacunas ou contradições detectadas na pesquisa, mas, pelo contrário, se propõe a construção (como o é todo o discurso histórico) de uma realidade parcelar, fragmentada, que está longe de responder a todas as nossas questões ou pelo menos de o fazer satisfatoriamente, constituindo por isso também um convite irrecusável a que mais pesquisa venha a ser feita.
Claro que nesta proposta de reconstituição de como funcionava o campo teatral em Lisboa nos três períodos considerados não cabe toda a informação que as autoras compulsaram (vejam-se as referências ao Diário do Governo, ao Boletim do Governo Civil ou ainda o número de periódicos consultados), porque não se trata de recolher e disponibilizar as fontes para o estudo do teatro em Portugal. Mas quem conhece grande parte dessas fontes não pode discordar da pertinência da selecção efectuada pelas autoras, tendo em vista o espaço de que dispunham (cerca de centena e meia de páginas), o público-alvo (alunos do ensino secundário, das licenciaturas em artes do espectáculo, professores e todos os que se interessam por teatro) e o objectivo da colecção (estimular o estudo das colecções do Museu do Teatro, divulgar a investigação sobre teatro), tal como não pode ficar insensivel à inteligência das conexões e interpretações propostas a partir dos documentos (veja-se o capitulo dedicado à censura teatral no I volume da colecção).

Cabe, por isso, uma chamada de atenção para a gestão das imagens que, obviamente utilizadas para ilustrar o texto, ganhariam em suscitar da parte do leitor um outro tipo de leitura. Para além de serem fonte de informação, as imagens existiram no seu tempo por si, como elementos, por vezes sofisticados, do sistema teatral que as autoras procuram reconstituir. Dai que, por exemplo, uma caricatura publicada em 1939, reportandose a uma figura do teatro no tempo de Almeida Garrett, mereça alguma análise: por ser uma caricatura, por transportar uma ideia de teatro que somos convidados a cruzar com o que sabemos ou não da prática teatral desse momento.

Também a reprodução de um painel de azulejos, de 1762, com figuras da commedia dell'arte (volume II, p. 79) merecia alguma explicação, visto que está por fazer o estudo da presença entre nós desses comediantes italianos, afigurando-se por isso muito interessante 0 contributo da história da arte, e neste caso da azulejaria portuguesa.

Na sua diversidade inevitável, tendo em conta as diferentes condições sociais e políticas de que emergem as práticas teatrais analisadas e a distinta orientação que as autoras vêm dando à investigação que desenvolvem, os três estudos mostram ter em comum a tentativa de identificar o sistema teatral português: as instituições que o constituem e o seu funcionamento, a sua relação com o poder, os públicos que o sustentam, a tipologia de espectáculos que ele é capaz de produzir, o lugar do actor, a política dos espaços teatrais, entre outros aspectos. Estes três volumes de uma colecção que se espera venha a ter continuidade, não se furtam a avançar interpretações, a fazer a crítica das posições e perspectivas expressas nos documentos ou inscritas nos factos que analisam. Fazem-no num discurso acessivel, didáctico quanto baste, por vezes irónico ou até humorístico, cuja leitura se aconselha vivamente. 